\title{
Preliminary data on backpack study
}

\begin{abstract}
University of California tested a device, IDT360 Back Pack "Protector" on backpacks that tremendously minimized both pressure in the upper as well as lower back on the participants and was found to be a great aid toward reducing back injury from weighted backpacks.
\end{abstract}

Keywords: Preliminary data, Backpack, Protector, Lower back, SEM, Back injuries
Volume 3 Issue 6 - 2015

Joseph Smith

Palmer College, USA

Correspondence: Joseph Smith, 2435 I5, Abvenue Vero Beach, FL 32960, USA, Email dcijoe@gmail.com

\section{Methods}

Three subjects were recruited for this preliminary experiment. The surface forces were measured on the lower back and upper back (directly over the dome). Each subject was tested with three backpack designs: control (design without a dome), small dome (detachable dome), and large dome. Each backpack was loaded with 11.5lbs of books.

\section{Results}

Data are presented as mean \pm SEM. Preliminary results suggest a reduction of upper back and lower back forces with increased dome size. It would be very interesting to find out where the load is transferred. In order to do that, we need to work with larger sensors that expand the entire surface area of the backpack. The dimensions of the current sensors used are $22 \mathrm{~cm} \mathrm{x} 4 \mathrm{~cm}$ (Figure 1).

We discovered three limitations with the study and each will be addressed in the future:

\section{The three groups were not randomized}

II. We did not pause between each measurement

III. These limitations are important and will be addressed. After repeated measurements we noticed that the sensors became less sensitive. We need to pause between measurements so that the sensors can decompress. By randomizing the groups we will avoid order effects as well.

IV. Although the strap on the backpack was fixed temporarily, it is still difficult to adjust the strap properly.

\section{Backpack "The Protector"}

The Backpack, "The Protector" is an engineered multidirectional protection device that easily attaches to any Backpack. The "The Protector" inserts attaches by hook and loop to the base making any Backpack more supportive and functional while providing the ultimate protection for the users back. The device has a square protective base made of closed cell foam which is sealed in the base and is coated with an epoxy like resin that once the base is unpeeled it cures as it is attached to any Backpack and becomes part of that Backpack (Figure 2)." The main feature of the Backpack is the Impact Dome Technology, the special attachable insert made from lightweight closed cell foam, providing protection, comfort and performance. The insert is adjustable for different heights. It reduces the pressure in both the upper and lower back, resulting in minimizing back injuries, such as sprains and strains.

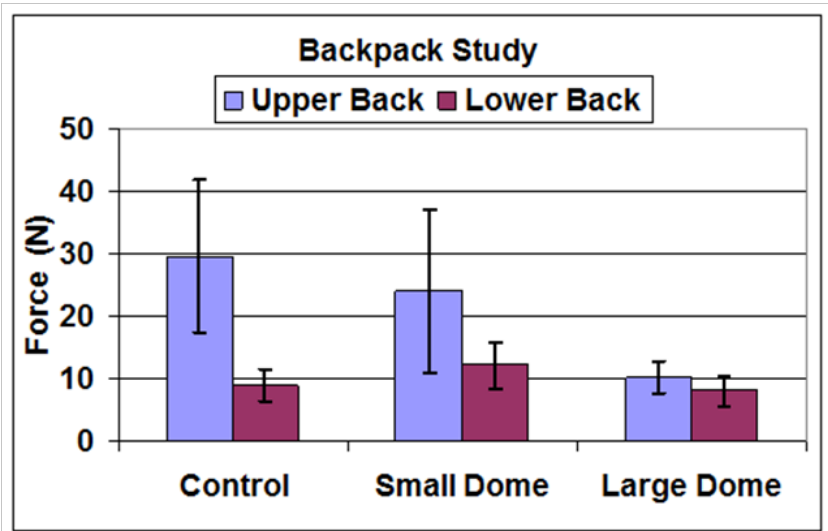

Figure I MRI T-2 weighted image demonstrating central triceps tear with retraction.

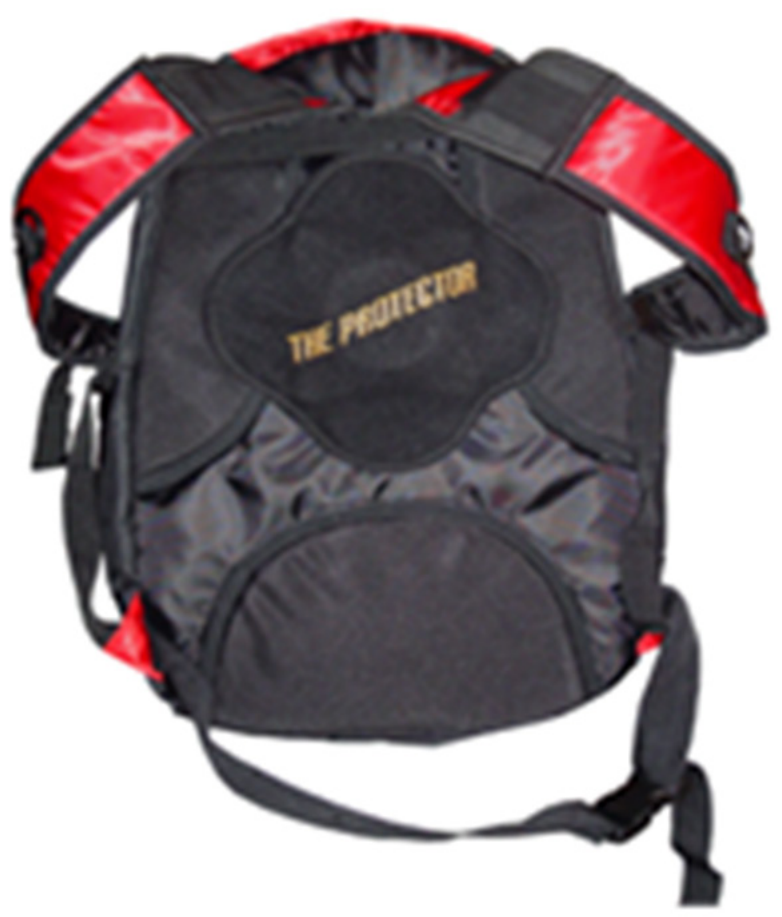

Figure 2 The Achilles graft sewn into the native remaining tendon. 
In clinical testing at the University of California, this patented engineered device was found to significantly reduce both upper and lower back pressure when compared to other Backpacks. Ideal for: School, Bicycling, Hiking, Camping, Fishing, Traveling, etc. First Aid/Sports Fusion.

\section{Acknowledgments}

None.

Conflicts of interest

None. 